\title{
Melanoma of the Uterus: A Review of the Literature
}

\author{
Lucy Kodzo-Grey Venyo ${ }^{1}$, Christiana Oluwashola Fatola ${ }^{2}$, Anthony Kodzo-Grey Venyo ${ }^{3 *}$
}

\begin{abstract}
Malignant Melanoma of the body of the Uterus (MMU) is rare. Various internet search engines were used. Information from 35 reports the earliest reported in 1974 and the latest in 2013 were identified. MMU can present as abnormal uterine bleeding and is most commonly reported in post-menopausal women. Reported ages of patients have ranged between 31 and 83 years. Primary and metastatic MMUs are very rare. The main environmental risk factor associated with cutaneous melanoma is exposure to ultraviolet radiation but the cause of primary MMU is unknown. There is no standard treatment in these cases but in patients who are fit to undergo surgery, usually radical hysterectomy, bilateral salpingo-oophorectomy and pelvic node dissection or sampling has been the main treatment in reported cases. Diagnoses of melanoma in reported cases were made histologically following surgery or endometrial biopsy. Thorough clinical examination is needed to rule out possible primary cutaneous sites of melanoma. Most patients tend to have a poor prognosis following presentation. Because MMU is so rare, it is difficult to research how to optimise treatment of patients. Ideally a multi-centre trial is needed regarding the treatment of the tumour in order to ascertain the best treatment to improve prognosis of patients. Primary or metastatic MMUs are rare and have been associated with poor prognosis. A multi-centre trial regarding the treatment of $M M U$ is required to arrive at a consensus opinion.
\end{abstract}

Keywords: Melanoma, Uterus, Immunohistochemistry, Melanins

\section{Introduction}

The uterus is an extremely rare site for the development of primary or metastatic malignant melanoma. Nevertheless, sporadic cases of melanoma of the body of the uterus have been reported. The ensuing paper which is divided into two parts (a) overview and (b) narrations from reported cases contains a review of the literature of melanoma of the uterus which includes narrations from reported cases of metastatic and primary malignant melanoma of the body of the uterus as well as carcinosarcoma with melanoma of the body of the uterus.

\section{Materials and Methods}

Various internet search engines including Google, Google Scholar, Educus, PubMed, and Up To Date, were used to look for case reports, case series and review papers on melanoma of the uterus. The following search words were used: Primary Melanoma of Uterus; Metastatic Melanoma of the uterus; Uterine Melanoma. Thirty-five documentations were found to be directly or indirectly pertinent to melanoma of the uterus and these were used to identify information on the presentation, investigation, management and management outcomes of melanoma of the uterus and to briefly outline the presentation, macroscopic features, microscopic features, the immunohistochemical characteristics of the tumour as well as to provide a narration of the documented cases of melanoma of the body of the uterus (endometrium and myometrium with the exclusion of uterine cervix).

\section{Results and Discussion}

Overview

General: The occurrence of melanoma of the uterus either as a primary or metastatic tumour is rare (1). Whilst metastatic melanoma of the uterus is rare primary melanoma of the uterus is extremely rare.

Metastatic Melanoma: Uterine melanoma metastases have been reported with the primaries originating from a number of organs including: skin, uvea, or hard palate. Melanoma may also metastasize from elsewhere to involve uterine polyps, including adenomyomas. It has also been stated that the cervix is the primary source in some cases of metastatic melanoma of the uterus $(1,2)$.

Primary Melanoma of uterus: Primary melanoma of the uterus may originate from lentigo or blue nevus $(1,3)$.

Presentation: Melanoma of the uterus may present as bleeding per vagina, premenopausal

(4), or post-menopausal (5).

Age: The reported ages of patients with melanoma of uterus have ranged from 31 years to 83 years but cases have been more commonly reported in the post-menopausal ages (4-6).

Received 21 April 2014, Accepted 7 September 2014, Available online 4 October 2014

${ }^{1}$ Queen Elizabeth Hospital Division of Anaesthesia Critical Care Unit, Gateshead, United Kingdom. ${ }^{2}$ Department of Ear Nose and Throat, North Manchester General Hospital, Manchester, United Kingdom. ${ }^{3}$ Department of Urology, North Manchester General Hospital, Manchester, United Kingdom.

*Corresponding Author: Anthony Kodzo-Grey Venyo, North Manchester General Hospital, Department of Urology, Manchester, United Kingdom. Tel: +441616246420, Email: akodzogrey@yahoo.co.uk 
Macroscopic Appearance: There may be obvious partially clotted blood within the uterine cavity. In case of endometrial involvement it may have a granular, nodular, and focally pigmented surface. If the entire uterus (myometrium) is involved there may be trans-mural infiltration by gray-white neoplasm involving it (4). The uterus may be bulky and also there may be evidence of enlarged pelvic lymph nodes involved. There may be evidence of melanin pigmentation.

Microscopic characteristics (see Figure 1 which illustrates the microscopic and immunohistochemical features): Microscopic examination may show infiltration of the uterus by sheets of pleomorphic and anaplastic, neoplasm com- posed of cells with large round to ovoid nuclei, prominent nucleoli, and scant cytoplasm. A number of the cells may be found to contain a yellowish-brown pigment which would be positive when stained with melanin (4).

Immunohistochemistry: Melanomas of the uterus on immunohistochemical staining, stain positively with MART1, (1) HMB45, (1) S-100, but negative with (1) CAM5.2, CK7, and CK20.

Treatment: There is no consensus opinion on the treatment of melanoma of the uterus but radical hysterectomy, bilateral salpingo-oophorectomy and pelvic lymph adenectomy, generally had been undertaken in the management of melanoma of the uterus by some authors (4).
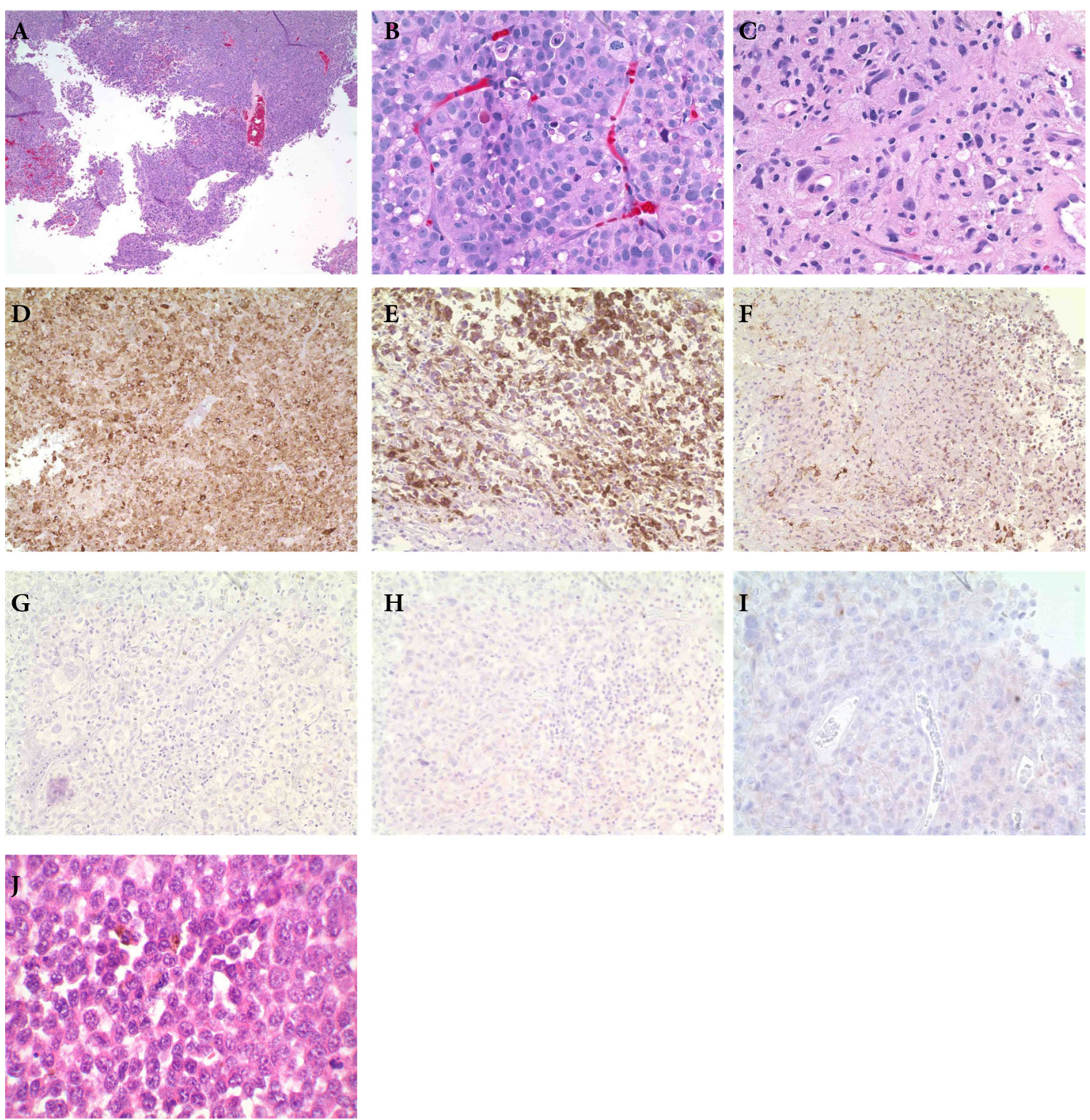

Figure 1. A, B and C) Showing H\&E microscopic pictures of melanoma of uterus at various magnifications with infiltration of the uterus by sheets of pleomorphic and anaplastic, neoplasm composed of cells with large round to ovoid nuclei, prominent nucleoli, and scant cytoplasm. D) MART 1. Immunohistochemistry showing positive staining with MART 1. E) HMB 45 Immunohistochemistry showing positive staining with HMB 45. F) Immunohistochemistry showing positive staining with S100. G) CAM 5.2 This shows negative staining for CAM 5.2. H) CK7 This shows negative staining for CK7. I) CK20, The figure shows negative staining for CK20. K) Tumour with prominent nucleoli and pigment. The specimen shows markedly pleomorphic cells with abundant eosinophilic cytoplasm and frequent large eosinophilic cytoplasm and frequent large nucleoli. The magnification of the figures was not stated at the PathologyOutlines.com website. Reproduced with permission granted by pathology outlines.com (1). 
Prognosis: It has been stated that melanoma of the uterus or cervix, whether it is primary or secondary melanoma is associated with poor prognosis (1).

\section{Narrations from reported cases (some of the reported cases are listed in Table 1)}

Berker et al. (6) reported a 39-year-old multigravida woman with a history of cutaneous malignant melanoma who presented with abnormal uterine bleeding. She had an endometrial biopsy and histological examination of the specimen showed neoplastic cells which contained brown granular pigment among the endometrial glands suggestive of melanoma. Immunohistochemical staining of the specimen revealed intense reactivity of the tumour cells with S-100 protein and HMB-45. These aforementioned features were reported to have confirmed the diagnosis of endometrial metastatic malignant melanoma. She had a complete clinical work-up which excluded metastatic spread to the brain, lungs, skeleton, and abdominal organs. She underwent total abdominal hysterectomy, bilateral salpingo-oophorectomy, and pelvic lymph node sampling. Based upon the histological characteristics of the specimen a final diagnosis of malignant melanoma which was limited to the endometrium was made. Berker et al. (6) concluded that abnormal uterine bleeding in patients with a history of malignancy should always alert the physician to consider the diagnosis of metastatic spread to the genital organ.

Coutts et al. (5) reported a case of uveal melanoma in an 83-year-old woman, who presented with post-menopausal bleeding due to metastasis. Three years prior to her admission, she had enucleation of the left eye for choroidal melanoma. She had received radiotherapy due to the presence of an extra-scleral extension. Three months prior to her presentation to the gynaecologists, she had a Computed Tomography (CT) scan which suggested a right orbital mass lesion. A bone scan showed widespread deposits in the spine, pelvis, ribs, femurs and humeri. She had an ultrasound scan which showed liver metastases. She presented with vaginal bleeding. She had endometrial biopsy and histological examination of the specimen revealed features that confirmed metastatic involvement of her endometrium by melanoma. She had further investigations which revealed widespread metastatic disease. She underwent clinical assessment and was found to be unfit to be administered chemotherapy. She died 2 months after her presentation and her autopsy revealed metastases in many sites which included the uterus, right ovary, kidney, mesentery, liver, lung, thyroid, bone marrow and skin. The right ovarian mass was confirmed to be a fibroma infiltrated by metastatic melanoma. The previous enucleated specimen was retrieved from the ophthalmology unit where she had the enucleation and histological review confirmed a choroidal melanoma of mixed histological type with an extrascleral extension. The immediate cause of her death was cardiac tamponade due to a malignant effusion secondary to cardiac metastasis. Coutts et al. (5) stated that:
- "Uveal melanoma differs from cutaneous melanoma in many ways, including its pattern of metastasis, and the fact that it exhibits latency with clinical evidence of metastasis sometimes appearing many years after the primary diagnosis."

- "Most patients develop metastasis in the liver, but some may present with metastasis to other sites."

- "Their case illustrated the widespread metastatic potential of uveal melanoma and highlighted the potential for unusual presentation of metastatic disease from this eye tumour."

Marschall et al. (7), reported a 53-year-old woman, who had a malignant melanoma of the hard palate for which she had previously undergone surgical excision. Seven years later, she was found to have developed bilateral pulmonary metastases and she was commenced on combination chemotherapy with cisplatin-dacarbazine. After her third cycle of chemotherapy, she had a routine blood count which revealed haemoglobin of $54 \mathrm{~g} / \mathrm{L}$. She had complained about having increasing fatigue. She had an abdominal examination which revealed a distended abdomen, but no evidence of tenderness and there was no source of blood loss. She had CT scan of the chest and abdomen which revealed: progressive bilateral pulmonary metastases with small bilateral pleural- effusions, diffuse intra-peritoneal fluid, and an enhancing lesion arising from the fundus of the uterus and right adnexa. Abdominal paracentesis yielded 2 litres of frank blood. In view of her on-going haemorrhage and the fact that she had 14 units of red blood cells, she underwent laparotomy. Another 3 litres of blood was aspirated from the peritoneal cavity and a solitary lesion with overlying clot was found on the fundus of the uterus. Hysterectomy and bilateral salpingo-oophorectomy was performed without any complication. Histological examination of the specimen revealed an invasive surface metastatic melanoma deposit with haemorrhage. One month later, she returned because of increasing shortness of breath. Her clinical examination findings as well as chest radiography were consistent with a large pleural effusion. A chest drain was inserted which drained 2.5 litres of blood. The drainage rapidly diminished and pleurodesis was performed. Marschall et al. (7) reported that at the time of the write up of their case report, 3 months after she had hysterectomy, the patient developed brain metastases, which were moderately responsive to steroids. She was otherwise well.

Di Tammaso et al. (8) stated that:

- "Rare cases of metastases to uterine polyps had been reported in the English literature but to the best of their knowledge metastasis to uterine adenomyomas had not previously been reported."

- "All these cases of metastases to uterine polyps were represented by breast cancer, and most of them involved tamoxifen associated polyps."

- "They reported firstly a case of cutaneous malignant melanoma metastatic to uterine adenomyoma. A computed tomography scan did not reveal any further evidence of disease, which suggested that the 
Table 1. List of reported cases of metastatic malignant melanoma of the body of the uterus and a summary of salient features

\begin{tabular}{|c|c|c|c|c|c|c|}
\hline $\begin{array}{l}\text { Author } \\
\text { Ref/Year/age }\end{array}$ & $\begin{array}{l}\text { Site of } \\
\text { primary }\end{array}$ & $\begin{array}{l}\text { Internal between } \\
\text { diagnosis of primary } \\
\text { and metastasis }\end{array}$ & $\begin{array}{l}\text { Stage and histology } \\
\text { of tumour }\end{array}$ & Imunohistochemistry & Treatment & $\begin{array}{l}\text { Outcome/duration of } \\
\text { follow-up }\end{array}$ \\
\hline $\begin{array}{l}\text { Marschall et al. } \\
\text { (7) /1993/53 yr. }\end{array}$ & Hard palate & 7 years & $\begin{array}{l}\text { Invasive surface } \\
\text { metastatic melanoma } \\
\text { deposit with } \\
\text { haemorrhage in left } \\
\text { side fundus of uterus; } \\
\text { also had bilateral } \\
\text { pulmonary metastasis } \\
\text { and was had } 3 \text { cycles } \\
\text { chemotherapy } \\
\text { cisplatin-dacarbazine }\end{array}$ & $\begin{array}{l}\text { Not stated in case } \\
\text { report }\end{array}$ & $\begin{array}{l}\text { Hysterectomy and } \\
\text { bilateral salpingo- } \\
\text { oophorectomy }\end{array}$ & $\begin{array}{l}\text { Alive } 3 \text { months with brain } \\
\text { metastases which were } \\
\text { moderately responsive to } \\
\text { steroids }\end{array}$ \\
\hline $\begin{array}{l}\text { Berker et al. } \\
(6) / 39 \mathrm{yr} \text {. }\end{array}$ & Skin & $\begin{array}{l}\text { Duration not } \\
\text { available authors }\end{array}$ & Endometrium & $\begin{array}{l}\text { Abdominal } \\
\text { hysterectomy, bilateral } \\
\text { lymph adenectomy } \\
\text { and pelvic lymph-node } \\
\text { sampling }\end{array}$ & $\begin{array}{l}\text { Imunohistochemistry } \\
\text { positive with S-100 } \\
\text { and HMB- } 45\end{array}$ & $\begin{array}{l}\text { Follow-up details not } \\
\text { provided and not available } \\
\text { to authors }\end{array}$ \\
\hline $\begin{array}{l}\text { Shuhalia et al. } \\
(28) / 2008 / 40 \\
\text { yr. }\end{array}$ & Left buttock & 18 months & $\begin{array}{l}\text { Tumour in placenta, } \\
\text { ovary and mesentery }\end{array}$ & HMB-45 positive & Cesarean section & $\begin{array}{l}\text { She died a week later } \\
\text { baby alive and well free of } \\
\text { tumour after } 18 \text { months }\end{array}$ \\
\hline $\begin{array}{l}\text { Suenaga et al. } \\
(27) / 1999 / 75 \\
\text { yr. }\end{array}$ & $\begin{array}{l}\text { Anterior } \\
\text { vagina wall }\end{array}$ & $\begin{array}{l}\text { Same time as } \\
\text { uterine metastases }\end{array}$ & $\begin{array}{l}\text { Anaplastic cells } \\
\text { with diminished } \\
\text { melanidization in } \\
\text { uterus }\end{array}$ & $\begin{array}{l}\text { Immunohistochemistry } \\
\text { details not available to } \\
\text { author } \\
\text { Serum } \\
\text { 5-S-cysteinyldopa and } \\
\text { adhesion molecule-1 } \\
\text { elevated }\end{array}$ & $\begin{array}{l}\text { Excision of anterior } \\
\text { vaginal wall, } \\
\text { bilateral inguinal } \\
\text { lymphadenectomy, } \\
\text { modified radical } \\
\text { hysterectomy, pelvic } \\
\text { node dissection }\end{array}$ & $\begin{array}{l}\text { She died } 5 \text { months later } \\
\text { with recurrent disease }\end{array}$ \\
\hline $\begin{array}{l}\text { Casey et al. } \\
\text { (4)/1974/31 yr. }\end{array}$ & $\begin{array}{l}\text { Skin right } \\
\text { scapula }\end{array}$ & $\begin{array}{l}8 \text { years [also } 6 \\
\text { months post- } \\
\text { partum] }\end{array}$ & $\begin{array}{l}\text { Gray-white neoplasm } \\
\text { involved the entire } \\
\text { uterus and nodular } \\
\text { focally pigmented } \\
\text { endometrium; } \\
\text { pleomorphic } \\
\text { anaplastic neoplastic } \\
\text { cells with extensive } \\
\text { vascular and } \\
\text { lymphatic invasion } \\
\text { and involvement of } \\
\text { left and right adnexa }\end{array}$ & $\begin{array}{l}\text { Immunohistochemistry } \\
*\end{array}$ & $\begin{array}{l}\text { Hysterectomy and } \\
\text { bilateral salpingo- } \\
\text { oophorectomy } \\
\text { plus imidazole and } \\
\text { carboximide }\end{array}$ & $\begin{array}{l}\text { She died } 1 \text { month later due } \\
\text { to massive intra-cerebral } \\
\text { haemorrhage secondary to } \\
\text { metastasis. She also had } \\
\text { metastases in her lungs, } \\
\text { liver, adrenal glands, heart, } \\
\text { mesentery, pleura and } \\
\text { peritoneum. }\end{array}$ \\
\hline $\begin{array}{l}\text { Pommerenke } \\
\text { et al. } \\
(26) / 1989 /^{*}\end{array}$ & Skin* & $*$ & $\begin{array}{l}\text { Metastasis in } \\
\text { endometrium }\end{array}$ & $*$ & $*$ & $*$ \\
\hline $\begin{array}{l}\text { Bauer et al. } \\
(25) / 1984 /^{*}\end{array}$ & $*$ & $*$ & $\begin{array}{l}\text { Metastasis to } \\
\text { endometrium }\end{array}$ & * & * & $*$ \\
\hline $\begin{array}{l}\text { Takeda et al. } \\
(24) / 1978 / *\end{array}$ & $\begin{array}{l}\text { Extra- } \\
\text { genital* }\end{array}$ & $*$ & $\begin{array}{l}\text { Metastasis to } \\
\text { endometrium }\end{array}$ & * & $*$ & $*$ \\
\hline $\begin{array}{l}\text { Nagy et al. } \\
(23) / 1990 / 38 \\
\text { yr. }\end{array}$ & Skin & 1.5 years & $\begin{array}{l}\text { Metastasis to } \\
\text { endometrium finely } \\
\text { granular cytoplasmic } \\
\text { pigment seen in the } \\
\text { smears was proven } \\
\text { to be melanin by the } \\
\text { use of potassium } \\
\text { permanganate } \\
\text { oxidation. }\end{array}$ & $*$ & Hysterectomy & $\begin{array}{l}\text { Follow-up details not } \\
\text { reported }\end{array}$ \\
\hline $\begin{array}{l}\text { Fambrini et al. } \\
(22) / 2008 / 52 \\
\text { yr. }\end{array}$ & Skin & 11 years & $\begin{array}{l}\text { Endometrium } \\
\text { involved with initial } \\
\text { myometrium invasion }\end{array}$ & $\begin{array}{l}\text { Immunohistochemistry } \\
\text { supported melanoma- } \\
*\end{array}$ & $\begin{array}{l}\text { Hysteroscopy, } \\
\text { hysterectomy and } \\
\text { bilateral salpingo- } \\
\text { oophorectomy } \\
\text { and pelvic lymph } \\
\text { adenectomy }\end{array}$ & $\begin{array}{l}\text { Alive and disease free after } \\
6 \text { months }\end{array}$ \\
\hline $\begin{array}{l}\text { Simeone et al. } \\
(21) / 2009 / 54 \\
\text { yr. }\end{array}$ & Skin & Same time & $\begin{array}{l}\text { Endometrium [genital } \\
\text { metastasis; also had } \\
\text { uterine fibromatosis] }\end{array}$ & $\begin{array}{l}\text { Immunohistochemistry } \\
\text { supported diagnosis }\end{array}$ & $\begin{array}{l}\text { Hysterectomy and } \\
\text { bilateral adnexectomy }\end{array}$ & $\begin{array}{l}\text { Details of follow-up not } \\
\text { available to authors }\end{array}$ \\
\hline $\begin{array}{l}\text { Bakelaar et al. } \\
(20) / 2008 / 49 y r\end{array}$ & Skin & $\begin{array}{l}\text { Time not available to } \\
\text { authors }\end{array}$ & $\begin{array}{l}\text { Tumour [ metastatic } \\
\text { melanoma to uterine } \\
\text { fibroid shown } \\
\text { by histological } \\
\text { examination] }\end{array}$ & $\begin{array}{l}\text { Immunohistochemistry } \\
\text { results not available to } \\
\text { authors }\end{array}$ & $\begin{array}{l}\text { Hysterectomy } \\
\text { and right inguinal } \\
\text { lymphadenectomy }\end{array}$ & $\begin{array}{l}\text { Follow-up data not } \\
\text { provided case reported } \\
\text { shortly after the operation }\end{array}$ \\
\hline
\end{tabular}




\section{Table 1. Continued}

\begin{tabular}{|c|c|c|c|c|c|c|}
\hline $\begin{array}{l}\text { Luxman et al. } \\
(19) / 1997 / 60 y r \text {. }\end{array}$ & Vulva & 6 months & $\begin{array}{l}\text { Metastasis to } \\
\text { endometrium with } \\
\text { invasion of inner two } \\
\text { thirds of myometrium }\end{array}$ & $\begin{array}{l}\text { Hysterectomy and } \\
\text { bilateral salpingo- } \\
\text { oophorectomy }\end{array}$ & $\begin{array}{l}\text { Immunohistochemical } \\
\text { staining positive with } \\
\text { vimentin, S-100, and } \\
\text { negative forHMB-45 }\end{array}$ & $\begin{array}{l}\text { Follow-up information } \\
\text { not provided [case was } \\
\text { reported not long after } \\
\text { operation] }\end{array}$ \\
\hline $\begin{array}{l}\text { Glaubitz et al. } \\
\text { (18)/1992/ } \\
\text { age details not } \\
\text { available to } \\
\text { authors }\end{array}$ & $\begin{array}{l}\text { Extra- } \\
\text { genital* }\end{array}$ & $*$ & $\begin{array}{l}\text { Metastasis to } \\
\text { endometrium }\end{array}$ & $\begin{array}{l}\text { Details not available to } \\
\text { authors }\end{array}$ & $\begin{array}{l}\text { Details not available } \\
\text { to authors }\end{array}$ & $\begin{array}{l}\text { Details not available to } \\
\text { authors }\end{array}$ \\
\hline $\begin{array}{l}\text { Varras et al. } \\
\text { 17)/2005/78yr. }\end{array}$ & $*$ & $*$ & $\begin{array}{l}\text { Uterus - myometrium } \\
\text { on scan [details } \\
\text { of histology not } \\
\text { available to authors] }\end{array}$ & $*$ & $*$ & $*$ \\
\hline $\begin{array}{l}\text { Heinig et al. } \\
(16) / 2001 / 60 y r .\end{array}$ & Skin & Duration not known & $\begin{array}{l}\text { Endometrium } \\
\text { metastasis }\end{array}$ & $*$ & $\begin{array}{l}\text { Immunohistochemistry } \\
\text { was positive with S-100 } \\
\text { and MART-1 }\end{array}$ & $\begin{array}{l}\text { Details of follow-up and } \\
\text { outcome not provided in } \\
\text { document }\end{array}$ \\
\hline $\begin{array}{l}\text { Bohlke et al. } \\
(15) / 58 \mathrm{yr} \text {. }\end{array}$ & $\begin{array}{l}\text { No other } \\
\text { site stated }\end{array}$ & $\begin{array}{l}\text { No history of a } \\
\text { primary tumour } \\
\text { stated } 6 \text { months } \\
\text { history of post- } \\
\text { menopausal } \\
\text { bleeding }\end{array}$ & $\begin{array}{l}\text { Endometrium - biopsy } \\
\text { showed markedly } \\
\text { pleomorphic cells, } \\
\text { abundant eosinophilic } \\
\text { cytoplasm; frequent } \\
\text { large eosinophilic } \\
\text { nucleoli; high mitotic } \\
\text { rate; multiple areas of } \\
\text { necrosis; no residual } \\
\text { endometrial tissue }\end{array}$ & $*$ & $\begin{array}{l}\text { MART1 (positive) } \\
\text { HMB45 (positive) } \\
\text { Moderate staining for } \\
\text { S100; } \\
\text { Tumour cells were } \\
\text { essentially negative } \\
\text { for keratins CAM5.2, } \\
\text { CK7 and CK20 with } \\
\text { only rare focal } \\
\text { staining }\end{array}$ & $*$ \\
\hline $\begin{array}{l}\text { Di Tammaso et } \\
\text { al. (8) }\end{array}$ & Skin & & $\begin{array}{l}\text { Metastatic } \\
\text { melanoma to uterine } \\
\text { adenoma(fibroid) }\end{array}$ & & & \\
\hline $\begin{array}{l}\text { Coutts et al. } \\
\text { (5)/2006/83 yr. }\end{array}$ & $\begin{array}{l}\text { Uvea (left } \\
\text { eye) } \\
3 \text { years later }\end{array}$ & $*$ & $\begin{array}{l}\text { Uterus with } \\
\text { metastatic deposits } \\
\text { in uterine fibroma } \\
\text { as well }\end{array}$ & $\begin{array}{l}\text { She was not fit for } \\
\text { chemotherapy or } \\
\text { surgery therefore no } \\
\text { treatment of curative } \\
\text { intent could be given }\end{array}$ & HMB45 & $\begin{array}{l}\text { Died with multiple } \\
\text { metastases but cause of } \\
\text { death and the immediate } \\
\text { cause of death was } \\
\text { cardiac tamponade due } \\
\text { to malignant effusion } \\
\text { secondary to cardiac } \\
\text { metastasis. }\end{array}$ \\
\hline
\end{tabular}

*Details not available to authors.

Reproduced from Pernick (1) and Bohlke and Stark (15).

metastatic localization might represent something more than a fortuitous case."

- "Based upon the aforementioned observations, it was suggested that a sub-set of malignant melanoma and breast cancer cells share a sort of "homing" phenomenon to polypoid lesions of uterus, due probably to the presence of some "chemokines" and their specific receptors."

- "Pathologists should be aware of this probability in order to carefully look for metastatic implants in similar lesions."

- "They had postulated that chemokine profile of neoplastic cells can be a useful tool in predicting metastatic targets."

Even though metastasis of primary melanoma metastasizing to or involving the uterus had been reported, it is worth knowing that melanoma of the cervix is rare and less than 100 cases had been reported and they have been more common in the vulva and vagina (2). Melanoma of the cervix usually manifests with vaginal bleeding (2,9-11). It has been reported after radiotherapy for squamous cell carcinoma of cervix (12). It is associated with poor prognosis with a historical 5 -year survival of $40 \%$ with stage 1 disease $(13,14)$. Macroscopically, melanomas of the cervix are seen as gray-blue-black nodules on the cervix (2). Bohlke et al. (case \#109) (15) reported a 58-year-old Asian female who presented with post-menopausal bleeding. Her clinical evaluation was insignificant. She had ultra-sound scan of abdomen and pelvis which revealed a grossly abnormal uterus with an area of centrally increased echogenicity which was suspicious of endometrial cancer. She had an endometrial biopsy. Histological examination of the specimen was reported to be diagnostic of undifferentiated malignant neoplasm suggestive of melanoma. The specimen was reported to have shown markedly pleomorphic cells with abundant eosinophilic cytoplasm and frequent large eosinophilic nucleoli. There was a high mitotic rate and multiple areas of necrosis. No residual endometrial or cervical tissue was identified. Immunohistochemistry of the specimen confirmed the diagnosis of melanoma. The tumour cells were immune-reactive for MART1 and HMB45. There was moderate staining for S-100. The tumour cells were essentially negative for keratins CAM5.2, CK7, and CK20 with only rare focal staining.

Heinig et al. (16) reported a rare case of endometrial metastasis of cutaneous malignant melanoma, mimicked by histological xanthomatous lesion. They stated that at the 
time of the report of their case, only about 10 other cases of endometrial metastasis of this malignancy had been reported. They reported a 60-year-old female who had post-menopausal bleeding. She had an un-pigmented malignant melanoma of skin before. She had fractionated curettage and tissue was sent for immunohistological examination. However due to xanthomatous regressive changes of the metastatic tissue, difficulties in the histological confirmation as a metastasis of an un-pigmented malignant melanoma occurred. But the tissue showed positive staining for S-100 and MART-1 when immunohistochemically stained, as did the primary tumour. They concluded that in case of atypical bleeding in patients with known malignant melanoma of the skin, endometrial metastasis should be excluded by gynaecologists.

Varras et al. (17) described the ultrasonographic appearance of malignant melanoma of the uterus. It had presented clinically as a large mass in a 78-year-old woman. They reported that trans-abdominal ultrasound scan revealed a solid uterine mass which measured $13 \mathrm{~cm} \times 11.5 \mathrm{~cm} \times$ $8.5 \mathrm{~cm}$ with inhomogeneous echo-texture and bright internal echoes. The tumour showed a diffuse spread inside the uterine corpus, and the endometrium was not demonstrated ultrasonographically.

In 1992 Glaubitz et al. (18) reported a case of endometrial metastasis of malignant melanoma. They stated that:

- Uterine metastases of extra-genital malignancies are rarely reported in the literature.

- Malignant melanoma as primary tumour is described more often than can be expected with regard to its relative incidence in comparison with other malignancies.

- If the uterus is involved in melanoma disease, mostly the cervix, and myometrium are affected, endometrial metastases are considered to be very rare.

- If the primary tumour (primary malignant melanoma) is known then bleeding abnormalities frequently lead to the diagnosis of uterine metastasis but rarely abnormal bleeding appears to be the first symptom of melanoma disease.

In 1997, Luxman et al. (19) stated that malignant melanoma is the second most common vulvar malignancy and the main sites of metastases are the superficial inguinal lymph nodes. They also stated that prior to the report of their case a case of endometrial metastasis of vulvar malignant melanoma had not been reported. Luxman et al. (19) reported a 60-year-old, post-menopausal woman who was diagnosed with metastatic uterine malignant melanoma from vulvar malignant melanoma. They stated that immunohistochemical stains of endometrial curettage were positive for Vimentin, and S-100 protein, and negative for HMB-45. Six months after she had undergone vulvectomy, right inguinal lymphadenectomy and immunotherapy, curettage was performed because of post-menopausal bleeding. Histological and immunohistochemical examinations showed metastatic malignant melanoma with the same staining reactivity as the primary vulvar neoplasm. The patient underwent hysterectomy and bilat- eral salpingo-oophorectomy which disclosed invasion of the endometrium and the inner two thirds of the myometrium. Luxman et al. (19) further stated that:

- Prior to their case report only 10 other cases of endometrial metastases from malignant melanoma had been reported which brought the total number of reported cases at that time to eleven.

- Their reported case was presumably the first report on endometrial and myometrial metastases from vulvar malignant melanoma.

Bakelaar et al. (20) reported a 49-year-old woman who presented with inguinal mass. Biopsy of the mass revealed an un-differentiated neoplasm. Further examination and CT scan revealed an enlarged, fibroid uterus. She underwent a total abdominal hysterectomy and right inguinal lymphadenectomy. Histological examination of the inguinal lymph node and the leiomyoma revealed metastatic melanoma.

Simeone et al. (21) reported a 54-year-old pluri-gravid woman who presented with metrorrhagia of unknown origin. In order to investigate her symptomatic post-menopausal bleeding and to exclude malignancy, such as endometrial carcinoma she underwent a diagnostic hysteroscopy and an endometrial biopsy. She was discharged with a diagnosis of uterine fibromatosis. She was however called back to undergo a complete laparoscopic hysterectomy and bilateral adnexectomy. During the operation, some metastases were found in the genital tract. Simeone et al. (21) stated that:

- An accurate physical examination allowed them to discover a cutaneous nevus, the excision and histological examination of which revealed its malignancy.

- The immunohistochemistry of the surgical sample was able to re-affirm the hypothesized relationship between the nevus and the metastases, thus leading to the diagnosis of malignant melanoma metastases in the genital tract.

- In patients with atypical uterine bleeding an accurate diagnosis is important to exclude tumoral pathology.

- In the post-menopausal period any Abnormal Uterine Bleeding (AUB) is considered abnormal and has to be investigated early in order to exclude any endometrial cancer.

- The nature of the uterine bleedings can be ascribed to atrophy, dysfunctional matters (dysfunctional uterine bleeding DBU), benign organic alterations, only in $7-10 \%$ of cases to endometrial cancer and more rarely to metastatic tumours as well as their case of melanoma.

- Physicians should be aware of such unusual possibilities in order to look carefully for metastatic implants in adenomyomas.

Fambrini et al. (22) reported the case of a 52-year-old woman with a history of excised cutaneous malignant melanoma. She had complained of abnormal uterine bleeding 11 years after her initial diagnosis. She underwent hysteroscopic examination which showed an endometrial lesion with polypoid shape. Endometrial biopsy was suggestive 
of melanoma. After complete clinical work-up ruling out other metastatic sites, the patient underwent total abdominal hysterectomy with bilateral salpingo-oophorectomy and pelvic lymph-adenectomy. The final histopathological and immunohistochemical examinations confirmed the diagnosis of endometrial melanoma with initial myometrial invasion. Fambrini et al. (22) further reported that after a 6-month follow-up period, the patient was disease free. They recommended that gynecologists should be aware that even after many years of negative follow-up, there is the possibility that abnormal uterine bleeding could represent the clinical expression of metastatic melanoma and thus offer a prompt diagnosis and personalized strategy of treatment.

Nagy et al. (23) reported a 38-year-old woman who was hospitalized with uterine bleeding and a history of malignant melanoma. Endometrial biopsy had already documented the presence of rare uterine metastases from a cutaneous lesion which was surgically removed from her back 1.5 years earlier. They stated that whilst a cervico-vaginal smear was negative, smears of a sample obtained from the uterine cavity by the Mi-Mark endometrial helix showed the cytomorphologic features of melanoma which corresponded to those seen in the primary lesion. The finely granular cytoplasmic pigment seen in the smears was proven to be melanin by the use of potassium permanganate oxidation. The patient then underwent hysterectomy. Nagy et al. (23) stated that their case demonstrated the potential utility of direct endometrial sampling in diagnosing difficult cases.

Takeda et al. (24) reported a case of cytologically diagnosed malignant melanoma metastatic to the endometrium. They reviewed the literature on extra-genital malignant neoplasms metastatic to the uterus. They documented the rarity of malignant melanoma which had metastasized to the endometrium. Also the cytological features of metastatic malignant melanoma along with a differential diagnosis of other lesions having pigmented cells such as primary pigmented lesions of the endometrium, primary malignant vaginal melanomas, benign pigmented lesions of the cervix and vagina, and pigmented conditions other than melanoma were described.

Bauer et al. (25) in 1984 reported a case of malignant melanoma which had metastasized to the endometrium along with a review of the literature on metastatic melanoma showing its rarity. They stated that malignant melanoma metastasizes to, many sites, including the lung, bone, liver, skin, and pancreas. They further stated that prior to the report of their case in 1984 four cases of melanoma metastatic to the endometrium had been reported in the literature.

Pommerenke and Tessman (26) reported a case of a metastasis in the endometrium from a malignant skin melanoma. They stated that difficulties for the differential diagnosis of the tumour can arise during histo- and cyto-diagnosis.

Casey et al. (4) reported a 31-year-old female. She was admitted with a 6-day history of moderate vaginal bleeding.
She was 6 months post-partum, after the birth of a full term and apparently normal infant. Since her delivery, the patient had experienced irregular menstrual periods with inter-menstrual spotting associated with cramping. For 2 weeks before her admission, she had general malaise, fatigue, and a 5-pound weight loss was noted. Her past medical history included the excision of a pigmented lesion of the skin overlying her right scapula 8 years previously in another institution. The lesion was considered to be border-line malignancy. Clinical examination revealed normal vital signs, a $1-2 \mathrm{~cm}$ in diameter non-tender mass in the lateral aspect of the left breast which had reportedly been there for several years and had not increased in size, and surgical scars in the right scapula region. Pelvic examination revealed a symmetrically enlarged uterus of about 8 to $10 \mathrm{~cm}$ in greatest dimension. There was moderate tenderness on palpation of the adnexa. A moderate amount of blood exuded from her cervical os. Chest X-ray revealed diffuse interstitial granular changes throughout both lung fields which were felt to be non-specific although granulomatous disease was considered. There were no discrete lesions. The results of her blood tests were reported as: $\mathrm{Hb}$ $11.5 \mathrm{gm} \%$; LDH elevated to 10 times the upper limit of normal. Other laboratory tests were normal. A pregnancy test was negative and her coagulation screen was normal. At operation, her uterus was found to be symmetrically enlarged and there were no other abnormal masses. She underwent hysterectomy and bilateral salpingo-oophorectomy. The uterus was symmetrically enlarged, and weighed 280 grams and measured $13 \mathrm{~cm}$ long and up to $8 \mathrm{~cm}$ in greatest diameter. There was a good amount of partially clotted blood within the uterine cavity which had a granular, nodular, and focally pigmented surface. Throughout the myometrium there was trans-mural infiltration by gray-white neoplasm involving virtually the entire uterus. Microscopic examination revealed that there was diffuse infiltration of the uterus by sheets of pleomorphic and anaplastic neoplasm composed of cells with large round to ovoid nuclei, prominent nucleoli, and scant cytoplasm. Many of the cells were found to contain a yellowish-brown pigment which was positive when stained with melanin. Extensive vascular and lymphatic invasion which involved the right and left adnexal structures were also observed. The microscopic slides of the skin lesion which was excised 8 years earlier were obtained. On review of the slides, the lesion was interpreted as superficial melanoma. Her post-operative treatment included Imidazole, and carboxamide. She did not have any demonstrable improvement. The patient died about 1 month after the diagnosis with massive intra-cerebral haemorrhage secondary to metastatic melanoma. Diffuse metastases involving the lungs, liver, adrenal glands, heart, mesentery, pleura, and peritoneum were also present.

Suenaga et al. (27) reported a 75-year-old Japanese woman. She presented with an enlarged uterus and two nodules on the anterior vaginal wall. She underwent wide excision of the anterior vaginal wall, bilateral inguinal lymph adenectomy, modified radical hysterectomy, and pelvic 
node dissection. Her serum 5-S-cysteinyldopa (5-S-CD) was elevated, however, her serum inter-cellular adhesion molecule-1 (ICAM-1) level was within normal limits. Histological examination of the vaginal wall revealed atypical melanocytes at the dermo-epidermal junction, and numerous melanin-containing granules in the cytoplasm of the tumour cells. The tumour in the uterus consisted of sheets of anaplastic cells with evidence of diminished melanization. Five months after her initial presentation, she developed a recurrence and died. The serum level of ICAM-1 was beyond the normal limit at the time of recurrence. Both the serum 5-S-CD and the ICAM-1 levels became elevated after recurrence and appeared to be correlated with diseases progression.

Shuhalia et al. (28) reported a 40-year-old woman, a grand multipara (Gravida 7 Para 6) who had presented with a cauliflower-like lesion $(4 \mathrm{~cm} \times 4 \mathrm{~cm} \times 1.5 \mathrm{~cm})$ on her left buttock 18 months earlier. A diagnosis of melanoma was made by histological examination of biopsy of the specimen. The histological examination showed thick sheets of polygonal malignant melanocytes with vesicular nuclei and prominent nucleoli. The tumour cells were seen in the epidermis and were deep in the dermis, but the lines of excision were not involved. She declined further treatment and defaulted follow-up. She was admitted with uncertain gestation, and presented with prolonged diarrhea of two weeks duration. She was previously diagnosed to have had melanoma. On examination she was found to have gross ascitis with hepatosplenomegaly. She was moribund with dehydration and compensated metabolic acidosis. She had an ultrasound scan which revealed a fetus corresponding to 29 weeks gestation with severe oligohydramnios. Cardiotocography showed recurrent late decelerations and she underwent an emergency caesarean section which confirmed widespread metastases to the ovaries, mesentery and placenta. A viable male fetus was delivered with features of intra-uterine growth restriction (he weighed 1.405 $\mathrm{kg}$ ). The baby survived but the mother died a week later. The male baby recovered well and was declared free of metastatic tumour after 18 months follow-up. Histological examination of the biopsies revealed nests of malignant melanocytes which exhibited round to oval nuclei, with finely granular cytoplasm in the ovaries, mesentery and placenta villi. There was no fetal infiltration. Immunohistochemical staining with HMB-45 was positive. Shuhalia et al. (28) stated that this case highlighted the importance of thorough assessment of placentas and babies of patients with melanoma for metastases.

Primary melanoma of uterus: In 1981, Schneider et al. (3) reported the first case of benign lentigo of the uterine cervix. They stated that their case provided further evidence that the cervix is able to form the entire spectrum of melanocytic lesions known to occur in skin. Schneider et al. (3) further stated that:

- Their review of the literature at the time of their case report in 1981 revealed 19 cases of primary malignant melanoma, of the cervix and 30 cases of nevus.

- Their reported case offered support that benign len- tigines may play a role as pre-malignant lesions of malignant melanoma not only in the skin, but also in mucous membrane (3)

Carcinosarcoma of uterus: Amant et al. (29) reported a 65 -year-old black woman who had a $3.0 \mathrm{~cm}$ endometrial tumour. It was a carcinosarcoma with a major epithelial and a less prominent mesenchymal component. The mesenchymal component was un-differentiated but one focus of chondroid differentiation was noted. The epithelial component showed papillary serous differentiation. Melanin pigment was observed in both epithelial and mesenchymal components. Immunohistochemical staining was positive for S-100 protein and HMB-45., confirming the presence of melanocytes. An endo-cervical focus of tumour also contained melanin. Electron microscopy showed large tumour cells with an irregularly indented nucleus and abnormal giant cytoplasmic melanosomes. They stated that at the time of the report of their case only one uterine carcinosarcoma with melanocytic differentiation had previously been reported.

Kajo et al. (30) stated that:

- Carcinosarcomas (CSs) are rare biphasic neoplasms of the female genital tract, with the presence of malignant epithelial and mesenchymal components.

- The occurrence of non-epithelial or non-mesenchymal differentiations in CSs is extremely rare.

Kajo et al. (30) reported a 54-year-old woman who had a history of treatment for carcinoma of the breast. She presented with a uterine tumour showing histological, immunohistochemical and ultra-structural features of an extremely rare carcinosarcoma, with signs of melanocytic differentiation. The lesion was a polypoid tumour mass which measured $7.0 \mathrm{~cm} \times 5.6 \mathrm{~cm}$. It arose from the endometrium and metastasized in the abdominal cavity as a malignant melanoma - the most aggressive component of carcinosarcoma. Despite adjuvant chemotherapy she died 8 months after the initial diagnosis due to the metastatic spread of carcinosarcoma. They stated that:

- In line with current knowledge, they assessed the melanocytic differentiation as one of a hypothetic differential line with the ability of multi-directional stem cell differentiation.

- To the best of their knowledge, only one case of uterine carcinosarcoma with melanocytic differentiation had been reported in the English literature.

Ariel et al. (31) in 1981 stated that malignant melanoma of the female genital tract comprises $3 \%$ of all melanomas afflicting females. The authors had treated 45 patients with melanoma of the vulva which was most common form. On presentation, $32 \%$ of the patients had metastases to the regional lymph nodes. The five-year-survival was 31.6\%. The treatment of choice was radical vulvectomy and radical groin dissection. Only 80 cases of melanomas of the vagina had been reported at the time of the publication of the paper, with cures being an extreme rarity. Forty cases of the female urethra melanoma had been reported in 1981 with only five survivors reported. Melanoma of the uterus was extremely rare with no cures recorded up to 
1981. Melanoma of the ovary may occur within a teratoma but most frequently was metastatic.

Some authors (32) stated that:

- In patients with cutaneous melanoma prognosis is primarily determined by the thickness of the primary lesion, mitotic rate, and presence and extent of metastatic disease.

- In contrast to other skin cancers (for example squamous cell carcinomas and basal cell carcinoma), melanomas are aggressive malignancies which may spread in an un-predictable manner to involve any organ of the body.

- Early diagnosis and treatment is the key to minimizing morbidity and mortality associated with melanoma of the skin.

- Information gathered from the literature review of melanoma of the uterus indicate that some patients develop the uterine melanoma of the uterus a long time after the development of melanoma of the skin and others are found to have melanoma of the skin at the time of the diagnosis of the uterine melanoma.

- In view of this any time a melanoma of the uterus is diagnosed it is important to establish whether or not there is a primary melanoma of skin or melanoma elsewhere.

- Whenever there is a diagnosis of melanoma of the uterus it is also important to establish whether or not the patient has ever had a cutaneous melanoma or melanoma previously elsewhere and if there is a history of previous melanoma elsewhere then the pathology slides of both the uterine melanoma and the previous melanoma should be reviewed by the pathologist.

Other authors (33) stated that:

- The main environmental risk factor associated with cutaneous melanoma is exposure to ultraviolet radiation.

- The risk is modified by high-risk genetic factors, the most frequent of which are mutations in the CDKN2A tumour suppressor gene.

- Other genetic factors including CDK4, Xeroderma pigmentosum, BRCA2 gene mutations, associated with an increased risk of melanoma had also been identified.

- Families who have known germ-line CDKN2A mutations are characterized by the fact that they have multiple family members with melanoma, an early age of onset, individuals with multiple primary melanomas, and co-existence with other primary tumours, particularly pancreatic cancer.

- Even when these criteria are present, germ-line mutations of CDKN2A are not common outside the context of families with known mutations.

- In the case of patients who are thought to be at risk of having an inherited susceptibility to melanoma due to a CDKN2A mutation, they had suggested genetic counseling with a qualified healthcare provider in order to receive education with regard to the risks and benefits of genetic testing and to discuss disease expression and the need for formalized testing.

- In the case of individuals who have known CDK2A mutation, they recommended close clinical surveillance and education with regard to melanoma risk-reducing behaviours such as sun screen use, sun avoidance.

- In the case of individuals who are thought to be at increased risk of having an inherited susceptibility to melanoma in which no germ-line gene mutation is detected or for individuals who have a personal and/or a family history of melanoma or who were identified as carrying a low-moderate risk allele for melanoma, they recommended education regarding melanoma risk-reducing behaviours and surveillance recommendations, which must be based upon the personal and family history.

The aforementioned statements relate to melanoma of the skin but whether they are applicable to melanomas of the uterus or not cannot be said for sure because melanomas of the uterus, either primary or secondary are extremely rare and to the knowledge of the authors there are no documented reports of genetic studies and environmental risk factor studies in relation to melanoma of the uterus. Armstrong et al. (32) stated that:

- Histopathology is the gold standard in the diagnosis of melanoma but in difficult cases immunohistochemistry or fluorescence in situ hybridization may be of help.

- Immunohistochemistry can be helpful in difficult cases of melanoma or in nodal melanoma metastases. The most widely used markers are S-100, MART-1, and HMB-45.

- Early studies had suggested that Fluorescent In Situ Hybridization (FISH) may be a useful technique for the pathological diagnosis of melanoma $(34,35)$. FISH procedure entails the cytogenetic analysis of melanocytic neoplasms through the detection of chromosomal aberrations. FISH may be useful particularly in situations in which the diagnosis of melanoma is uncertain.

In summary, metastatic malignant melanoma of the uterus is very rare. Primary malignant melanoma or carcinosarcoma of the body of uterus is extremely rare. Cases of metastatic malignant melanoma of the body of the uterus have been reported in patients aged between 31 and 83 years. Melanoma of the uterus tends to present as either pre-menopausal or post-menopausal bleeding. Diagnosis of melanoma of the uterus has been based upon the characteristic histological findings and upon immunohistochemical staining of the tumour with S-100, MART-1 or HMB-45. In patients who are fit to undergo surgery, radical hysterectomy, bilateral salpingo-oophorectomy and pelvic node dissection/sampling has been the main treatment modality used in reported cases. So far, the prognosis of reported cases of melanoma of the body of the uterus, have remained poor. 


\section{Conclusion}

Melanoma of the body of the uterus is a rare tumour. Metastatic malignant melanoma may be diagnosed a long time after a primary melanoma elsewhere had been diagnosed and treated or at times the primary malignant melanoma may be contemporaneously diagnosed.

When a diagnosis of malignant melanoma of the uterus is established, clinicians should endeavour to search whether or not there is a primary melanoma elsewhere or whether or not there is a past history of melanoma. If there is a past history of melanoma elsewhere, then the pathologists should review the histological and immunohistochemical characteristics of both tumours.

In view of the fact that melanoma of the uterus is rare and its prognosis is poor, a multi-centre trial regarding the treatment of the tumour is necessary to ascertain the best treatment option that would help improve upon the survival of patients.

\section{Ethical issues}

We have no ethical issues to declare.

\section{Conflict of interests}

We have no conflict of interest to declare.

\section{Funding}

We have not had any funding related to the write up of this paper.

\section{Acknowledgments}

Dr. Nat Pernick President of Pathology Outlines.com for granting the authors copyright permission to reproduce figures from Pathology Outlines.com in the article.

\section{References}

1. Pernick N. Uterus: Other tumors Melanoma of uterus. October 2011. Available from: http://www. pathologyoutlines.com/topic/uterusmelanoma.html

2. Pernick N. Cervix-cytology: Sarcoma/lymphoma/ other Melanoma. 2011 June 27. Available from: http://www.pathologyoutlines.com/topic/ cervixcytologymelanoma.html

3. Schneider V, Zimberg ST, Kay S. The pigmented portio: benign lentigo of the uterine cervix. Diagn Gynecol Obstet 1981;3(3):269-72.

4. Casey JH, Shapiro RF. Metastatic melanoma presenting as primary uterine neoplasm: a case report. Cancer 1974;33(3):729-31.

5. Coutts MA, Borthwick NJ, Hungerford JL, Cree IA. Post-menopausal bleeding: a rare presentation of metastatic uveal melanoma. Pathol Oncol Res 2006;12(3):184-7.

6. Berker B, Sericelik A, Kayousuz G, Unlu C, Ortac F. Abnormal uterine bleeding as a presenting sign of metastasis to endometrium in a patient with a history of cutaneous malignant melanoma. Gynecol Oncol 2004;93(1):252-6.

7. Marschall J, Kennedy RS, Kanthan R. Nontraumatic massive hemoperitoneum from melanoma metastatic to the uterus. Can J Surg 2002;45(6):461-2.

8. Di Tammaso L, Rahal D, Bresciani G, Runcalli M. Cutaneous melanoma metastatic to uterine adenomyoma: report of a case. Int J Surg Pathol 2005;13(2):223-5.

9. Gupta J, Singh S, Mandal AK. Primary malignant melanoma of cervix - a case report. Indian J Cancer 2005;42(4):201-4.

10. Makovitzky J, Schmitz C, Vogt-Weber B, Nizze H. Primary malignant melanoma of the cervix uteri: a case report of a rare tumor. Anticancer Res 2003;23(2A):1063-7.

11. Furuya $M$, Shimuzu $M$, Nishihara $H$, Ito $T$, Sakuraqi N, Ishikura $\mathrm{H}$, et al. Clear cell variant of malignant melanoma of the uterine cervix: a case report and review of the literature. Gynecol Oncol 2001;80(3):409-12.

12. Benson R J, Tan LT. Radiation-induced malignant melanoma of the cervix. Clin Oncol (R Coll Radiol) 2000;12(4):234-7.

13. Mordel N, Mor-Yosef S, Ben-Baruch N, Anteby SO. Malignant melanoma of the cervix: case report and review of the literature. Gynecol Oncol 1989;32(3):375-80.

14. Ma SQ, Bai CM, Yu XH, An YT, Lang JH. Primary malignant melanoma of the cervix: report of four cases and review of the literature. Zhonghua Fu Chan Ke Za Zhi 2005;40(3): 183-5.

15. Bohlke A, Stark M. Case of the Week 24 January 2008 \# 109 in Pernick N. Uterus Other tumors Melanoma of uterus. October 2011. Available from: http://www. pathologyoutlines.com/topic/uterusmelanoma.html

16. Heinig J, August C, Beckmann V, Konieczny A. Endometrial metastasis of cutaneous melanoma. Zentralbl Gynakol 2001;123(9):534-5.

17. Varras M, Kassanos D, Tzaida O, Bournas N, Panaglopoulos N, Chrelias C, et al. Ultrasonographic evaluation of a uterine malignant melanoma presenting as a large pelvic mass. J Clin Ultrasound 2005;33(8):424-6.

18. Glaubitz $M$, Jantzen $K$, Amthor M. [Uterine metastases of malignant melanoma]. Gerbutsshile Frauenheikd $1992 ; 52(2): 92-5$. [In German]

19. Luxman D, Jossiphov J, Cohen JR, Wolf Y, David MP. Uterine metastasis from vulvar malignant melanoma: A case report. J Reprod Med 1997;42(4):244-6.

20. Bakelaar RT, Soper JT, Lutman CV. Cutaneous malignant melanoma metastatic to uterineleiomyoma: a case report. J Reprod Med 2008;53(9):697-9.

21. Simeone S, Laterza MM, Scaravilli G, Capuano S, Serao M, Orabona $\mathrm{P}$, et al. Malignant melanoma metastasizing to the uterus in a patient with atypical postmenopause metrorrhagia A case report. Minerva Ginecol 2009;61(1):77-80.

22. Fambrini M, Anderson K L, Buccoliero AM, Pieralli A, Livi L, Marchionni M. Late solitary metastasis of cutaneous malignant melanoma presenting as 
abnormal uterine bleeding. J obstet Gynaecol Res 2008;34(4 Pt 2):731-4.

23. Nagy P, Osaba I, Kadas I. Malignant melanoma metastatic to the endometrium cytologic findings in a direct endometrial sample. Acta Cytol 1990;34(3):382-4.

24. Takeda M, Diamond SM, DeMarco M, Quinn DM. Cytologic diagnosis of malignant melanoma metastatic to the endometrium. Acta Cytol 1978;22(6):503-6.

25. Bauer RD, McCoy CP, Roberts DK, Fritz G. Malignant melanoma metastatic to the endometrium. Obstet Gynecol 1984;63(2):264-8.

26. Pommerenke F, Tessmann D. [ Endometrial metastasis of a malignant melanoma of the skin]. Zentraibl Gynakol 1989;111(5):324-8. [In German]

27. Suenaga Y, Katabuchi H, Okamura H, Kageshila T, Ono T. Increased serum levels of 5-S-cysteinyldopa and intercellular adhesion molecule- 1 in a patient with a uterine amelanotic metastasis from a primary vagina malignant melanoma. Gynecol Oncol 1999;72(1):107-10.

28. Shuhalia A, Rohaizak M, Phang KS, Mahdy ZA. Maternal melanoma with placental metastasis. Singapore Med J 2008;49(3):e71-2.

29. Amant F, Moerman P, Davel GH, De Vos R, Vergote $\mathrm{I}$, Lindeque $\mathrm{BG}$, et al. Uterine carcinoma with melanocytic differentiation. Int J Gynecol Pathol 2001;20(2):186-90.

30. Kajo K, Zubor P, Spacek J, Ryska A. Carcinosarcoma of the uterus with melanocytic differentiation. Pathol Res Pract 2007;203(10):753-8.

31. Ariel IM. Malignant melanoma of the female genital system: a report of 48 patients and review of the litera74ture. J Surg Oncol 1981;16(4):371-83.

32. Armstrong AW, Minn MC, Atkins MB, Tsao $\mathrm{H}$, Corona R. Pathologic characteristics of melanoma. 2013 Jul. Available from: www.uptodate.com/ contents/pathologic-characteristics-of-melanoma?de tectedLanguge $=$ en\&so.

33. Tsao H, Gabree MJ, Atkins MB, Raby BA, Rose ME. Inherited susceptibility to melanoma. Jul 2013. Available from: http://www.uptodate.com/contents/ inherited-susceptibility-to-melanoma?topicKey=ON C\%2F7624\&el

34. Gerami P, Mafee M, Lurtsbarapa T, Guitart J, Haghighat Z, Newman M. Sensitivity of fluorescence in situ hybridization for melanoma diagnosis using RREB1, MYB, Cep6, and 11q13 probes in melanoma subtypes. Arch Dermatol 2010;146(3):273-8.

35. Gerami P, Wass A, Mafee M, Fang Y, Pulitzer MP, Busam KJ. Fluorescence in situ hybridization for distinguishing nevoid melanomas from mitotically active nevi. Am J Surg Pathol 2009;33(12):1783-8.

Copyright $\odot 2014$ The Author(s); This is an open-access article distributed under the terms of the Creative Commons Attribution License (http://creativecommons.org/licenses/by/4.0), which permits unrestricted use, distribution, and reproduction in any medium, provided the original work is properly cited. 